\title{
Decellularized versus cryopreserved pulmonary allografts for right ventricular outflow tract reconstruction during the Ross procedure: a meta-analysis of short- and long-term outcomes
}

Adham Ahmed $^{1 *+} \mathbb{0}$, Sarah Ahmed ${ }^{2 \dagger}$, Kathryn S. Varghese ${ }^{1}$, Dave M. Mathew ${ }^{1}$, Roshan Pandey ${ }^{3}$, Dillon O. Rogando ${ }^{1}$, Stephanie A. Salazar ${ }^{1}$, Peter J. Fusco ${ }^{1}$ and Kenneth H. Levy ${ }^{1}$

\begin{abstract}
Background: The ideal conduit for repair of the right ventricular outflow tract (RVOT) during the Ross procedure remains unclear and has yet to be fully elucidated. We perform a pairwise meta-analysis to compare the short-term and long-term outcomes of decellularized versus cryopreserved pulmonary allografts for RVOT reconstruction during the Ross procedure.

Main body: After a comprehensive literature search, studies comparing decellularized and cryopreserved allografts for patients undergoing RVOT reconstruction during the Ross procedure were pooled to perform a pairwise metaanalysis using the random-effects model. Primary outcomes were early mortality and follow-up allograft dysfunction. Secondary outcomes were reintervention rates and follow-up endocarditis. A total of 4 studies including 1687 patients undergoing RVOT reconstruction during the Ross procedure were included. A total of 812 patients received a decellularized pulmonary allograft, while 875 received a cryopreserved pulmonary allograft. Compared to cryopreserved allografts, the decellularized group showed similar rates of early mortality (odds ratio, $0.55,95 \%$ confidence interval, $0.21-1.41, P=0.22$ ). At a mean follow-up period of 5.89 years, no significant difference was observed between the two groups for follow-up allograft dysfunction (hazard ratio, 0.65, 95\% confidence interval, 0.20-2.14, $P=0.48$ ). Similarly, no difference was seen in reintervention rates (hazard ratio, $0.54,95 \%$ confidence interval, 0.09 $3.12, P=0.49$ ) nor endocarditis (hazard ratio, $0.30,95 \%$ confidence interval, $0.07-1.35, P=0.12$ ) at a mean follow-up of 4.85 and 5.75 years, respectively.

Conclusions: Decellularized and cryopreserved pulmonary allografts are associated with similar postoperative outcomes for RVOT reconstruction during the Ross procedure. Larger propensity-matched and randomized control trials are necessary to elucidate the efficacy of decellularized allografts compared to cryopreserved allografts in the setting of the Ross.
\end{abstract}

Keywords: Aortic valve, Homograft, Allograft, Decellularized, Ross, Ross-Yacoub, Aortic valve replacement

*Correspondence: aahmed018@citymail.cuny.edu

${ }^{\dagger}$ Adham Ahmed and Sarah Ahmed have contributed equally to this work

${ }^{1}$ CUNY School of Medicine, 1589 Amsterdam Avenue, New York, NY

10031, USA

Full list of author information is available at the end of the article

\section{Background}

The Ross procedure continues to be a viable form of aortic valve replacement with favorable hemodynamics and long-term viability. Currently, cryopreserved pulmonary 
allografts are the golden standard for repair of the right ventricular outflow tract reconstruction (RVOT) during the Ross procedure, but their use has been associated with increased risk of reoperation and immunological responses. Conversely, the decellularized grafts have been proposed to achieve the favorable hemodynamics associated with a pulmonary allograft, while reducing the risk of premature graft stenosis. While previous isolated observational studies have reported the clinical outcomes of decellularized and cryopreserved allografts use in the Ross procedure, consensus over the optimal strategy is still lacking. Herein, we perform a pairwise meta-analysis to compare the short-term and long-term outcomes of decellularized versus cryopreserved pulmonary allografts for RVOT reconstruction during the Ross procedure.

\section{Introduction}

For younger patients undergoing aortic valve replacement, the Ross procedure offers an alternative to artificial conduits and has been shown to have favorable hemodynamics and long-term viability [1]. Additionally, the use of a living valve substitute bypasses the risk of life-long coagulation therapy [2] and increased risk of structural valve deterioration [3] associated with mechanical and bioprosthetic valves, respectively. Following the insertion of the pulmonary autograft in the aortic position during the Ross procedure, attention is directed toward the repair of the right ventricular outflow tract (RVOT). While cryopreserved pulmonary allografts are the current golden standard for RVOT reconstruction during the Ross procedure [4], their use has been associated with increased risk of reoperation due to calcifications and damage to the graft by host immunological response [5]. Alternatively, the use of decellularization techniques has been proposed as a means of providing the optimal hemodynamic associated with a pulmonary allograft, while reducing the risk of premature graft stenosis $[6$, 7]. Previously, the clinical outcomes of decellularized and cryopreserved allografts use in the Ross procedure have been reported through isolated observational studies [8-11], but consensus over the optimal strategy is still lacking. Herein, we perform a pairwise meta-analysis to compare the short-term and long-term outcomes of decellularized versus cryopreserved pulmonary allografts for RVOT reconstruction during the Ross procedure.

\section{Methods}

\section{Comprehensive search strategy}

This study was registered on the PROSPERO database of systematic reviews (ID: CRD42021247939) and followed the Meta-analysis of observational studies in epidemiology (MOOSE) proposal (Additional file 1: Fig. S1) [12]. Institutional ethical approval was not required as no individual patient data were utilized during this meta-analysis. A comprehensive literature search was performed on May 1, 2021, to find trials and observational cohort investigations comparing the use of decellularized and cryopreserved pulmonary allografts for RVOT reconstruction in patients undergoing the Ross procedure. The search strategy was performed with no restrictions on PubMed (National Institute of Health), Ovid EMBASE, and Scopus and utilized the terms: 'Ross,' 'Ross-Yacoub,' 'decellularized,' 'cryopreserved,' 'allograft,' and 'homograft.' Recently published articles making comparisons between allograft use during the Ross procedure were hand-searched and screened. A full outline of the search strategies for PubMed, EMBASE and Scopus is collated in Additional file 1: Table S1.

\section{Study screening}

The literature search yielded 6768 results (Fig. 1). After deduplication, two investigators (S.A. and R.P.) individually reviewed 6488 titles and abstracts of remaining studies using pre-defined criteria. Any discrepancies were resolved by the senior author (K.H.L.). Articles were eligible for inclusion if they were published in the English language and directly compared outcomes of patients undergoing RVOT reconstruction during the Ross procedure using either a decellularized or cryopreserved pulmonary allograft. Studies were excluded if they were abstracts, posters, animal studies, case series, commentaries, presentations, or systematic reviews. Studies reporting outcomes for single-arm interventions were also excluded from analysis.

Next, full texts of remaining studies assessed for eligibility. Additionally, any relevant citations for included articles were screened for inclusion. For overlapping patient cohorts, only the study with the larger sample size was included. Full texts were evaluated by two authors (K.S.V. and D.M.M.) and followed by confirmation of accuracy by a third investigator (A.A.).

\section{Quality assessment}

Using the Newcastle-Ottawa Scale for observational studies, two authors (S.A. and R.P.) independently reviewed included studies for quality; discrepancies were resolved by discussion to reach consensus (Additional file 1: Table S2) [13].

\section{Data collection}

Two authors (D.O.R. and S.A.S.) recorded data for included studies independently, and their collected data were then verified by a third investigator for accuracy (P.J.F.). Whenever reported by an included study, propensity-matched data were extracted for our analysis. 

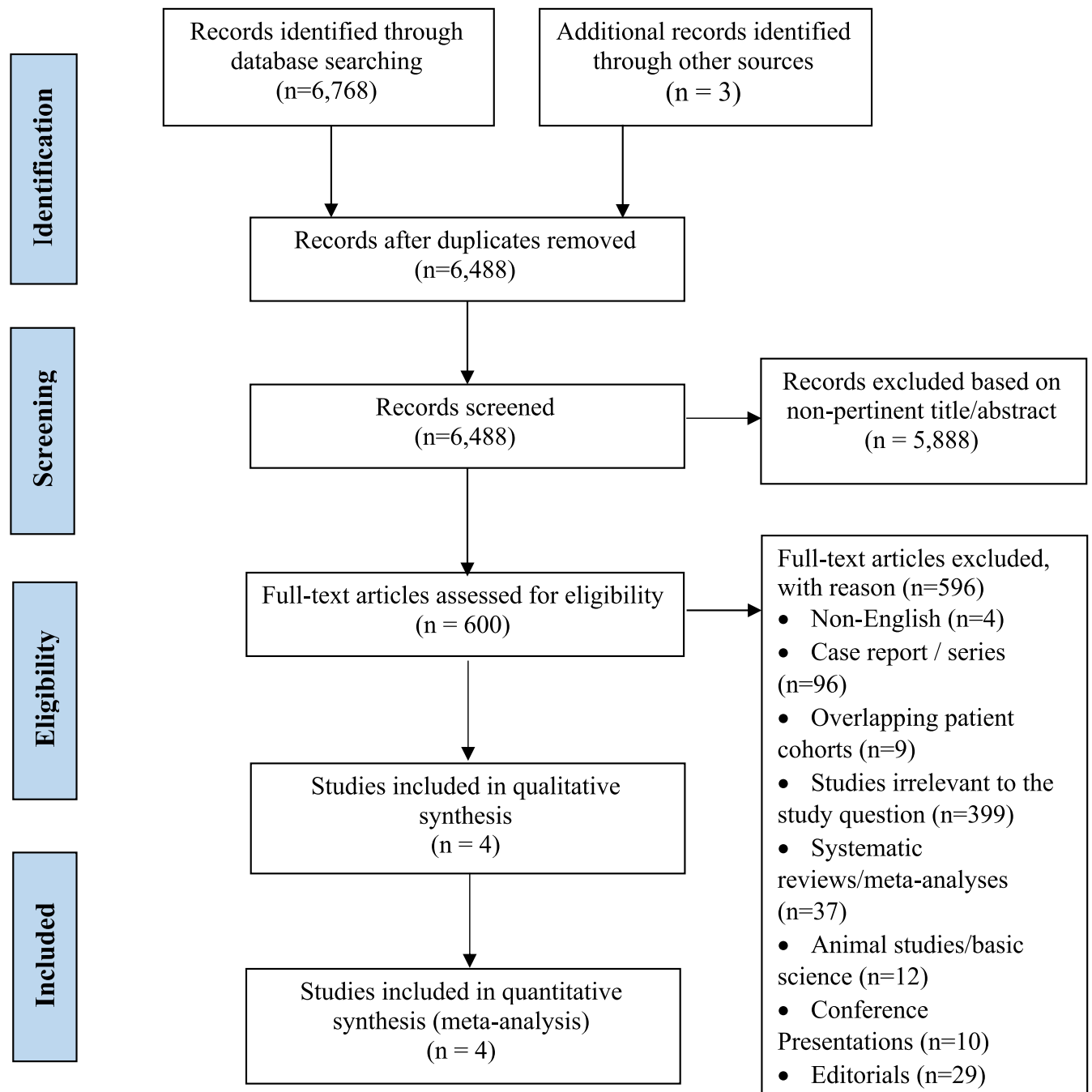

Full-text articles excluded, with reason $(\mathrm{n}=596)$

- Non-English $(\mathrm{n}=4)$

- Case report / series $(n=96)$

- Overlapping patient cohorts $(n=9)$

- Studies irrelevant to the study question $(\mathrm{n}=399)$

- Systematic reviews/meta-analyses $(\mathrm{n}=37)$

- Animal studies/basic science $(\mathrm{n}=12)$

- Conference

Presentations $(\mathrm{n}=10)$

- Editorials $(\mathrm{n}=29)$

Fig. 1 Preferred reporting items for systematic reviews and meta-analysis (PRISMA) flowchart of our analysis

When available, information was collected regarding: study information [cohort size, period of study, institution of study, and country of study] (Table 1), patient baseline characteristics [age, gender, body mass index (BMI), body surface area (BSA), New York Heart
Association (NYHA) Class III/IV, presenting etiology (congenital, degenerative, endocarditis, rheumatic, prosthetic valve dysfunction)], and comorbidities [high blood pressure, angina, atrial fibrillation, coronary artery disease, smoking status, peripheral artery disease, peripheral

Table 1 Summary of included studies

\begin{tabular}{lllllrr}
\hline References & Study period & Hospital & Country & Types of study & $\begin{array}{l}\text { Decellularized } \\
\text { allograft }\end{array}$ & $\begin{array}{c}\text { Cryopreserved } \\
\text { allograft }\end{array}$ \\
\hline Bechtel [8] & $2000-2002$ & University of Luebeck & Germany & Retrospective & 23 & 49 \\
Brown [1 1] & $2000-2005$ & Multicenter & USA & Retrospective & 193 & 665 \\
Chauvette [9] & $2011-2019$ & Multicenter, Canadian Ross Registry & Canada & Retrospective & 466 & 31 \\
Etnel [10] & $1995-2017$ & Santa Case de Curitiba & Brazil & Retrospective/PSM & 130 & 130 \\
\hline
\end{tabular}


vascular disease, cerebrovascular disease, congenital disease, chronic obstructive pulmonary disease, renal insufficiency, prior cardiothoracic operations, left ventricular ejection fraction, and diabetes mellitus] (Additional file 1: Table S3). Additionally, we recorded data pertaining to operative details [operative technique (root replacement, inclusion, subcoronary implantation, redo allograft), allograft mean diameter $(\mathrm{mm}), \mathrm{ABO}$ blood type mismatch, RVOT augmentation] (Additional file 1: Table S4).

\section{Statistical analysis}

All conducted statistical analyses were performed in Review Manager (RevMan 5.4.1, The Cochrane Collaboration, 2020) [14] using the Mantel-Haenszel method. For all analyses, a 2 -tailed $P$ value $<0.05$ was deemed statistically significant. Using the random-effects model, we pooled early outcomes as odds ratio (OR) and their 95\% confidence intervals (CIs). All of our follow-up outcomes (based on longest available follow-up) were pooled as a natural logarithm of the hazard ratio (HR) using the generic inverse variance method to account for any heterogeneity between follow-up durations for each intervention group. We recorded heterogeneity as low $\left(I^{2}=0-25 \%\right)$, moderate $\left(I^{2}=25-50 \%\right)$, or high $\left(I^{2}>50 \%\right)$ using Higgins' and Thompson's $I^{2}$ statistic [15] (Figs. 2, 3, 4 and 5). We assessed publication bias using a funnel plot (Additional file 1: Figs. S2.1-S2.4).

\section{Outcomes and definitions}

Early mortality and follow-up allograft dysfunction were our primary outcomes. Our secondary outcomes were reintervention rates and follow-up endocarditis. Outcome definitions in this analysis corresponded to the definitions reported in our included studies (Additional file 1: Table S5).

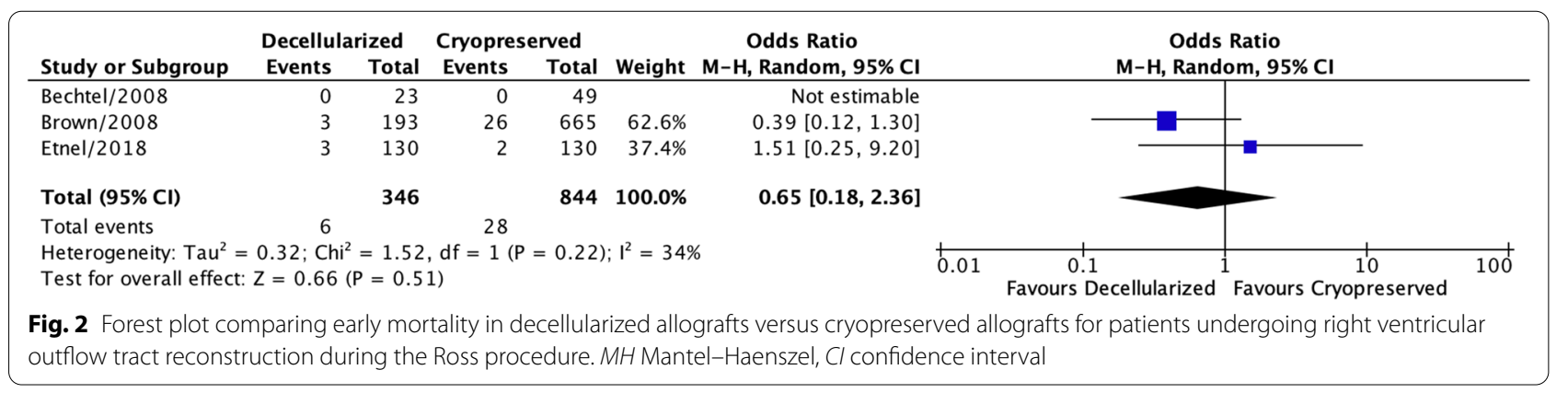

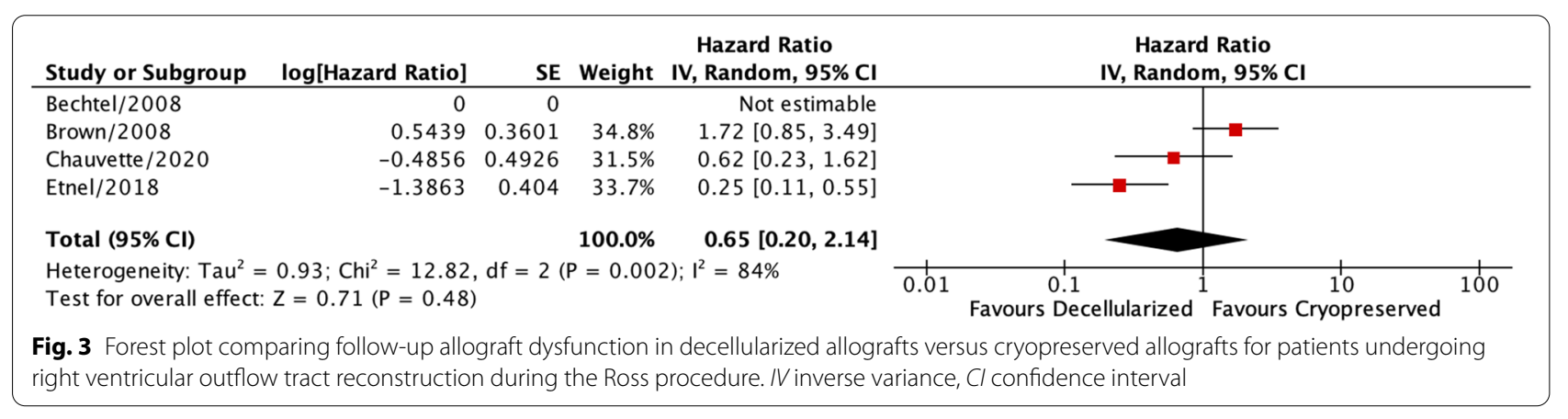

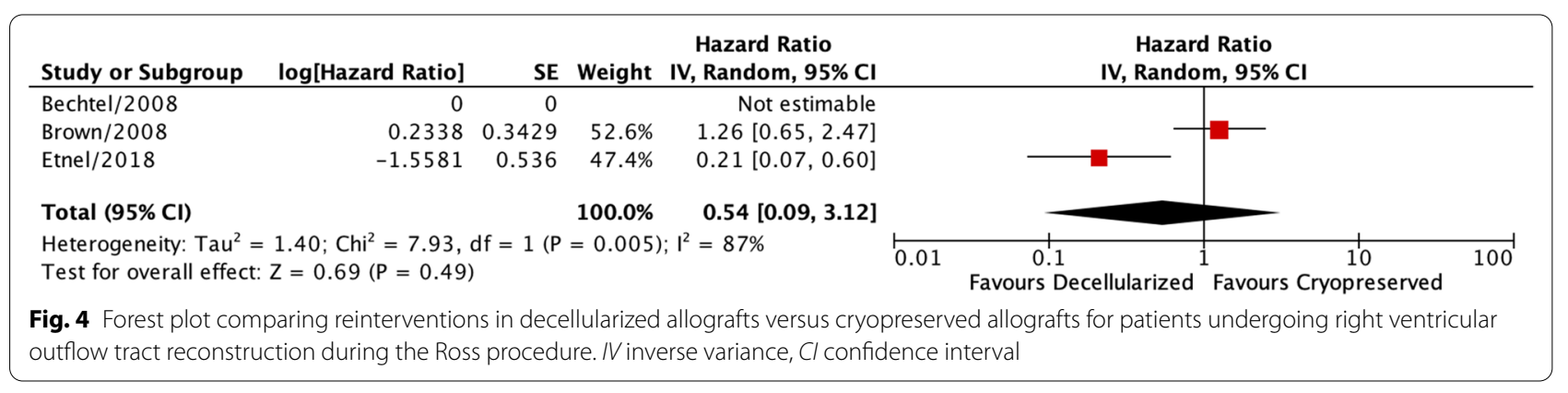




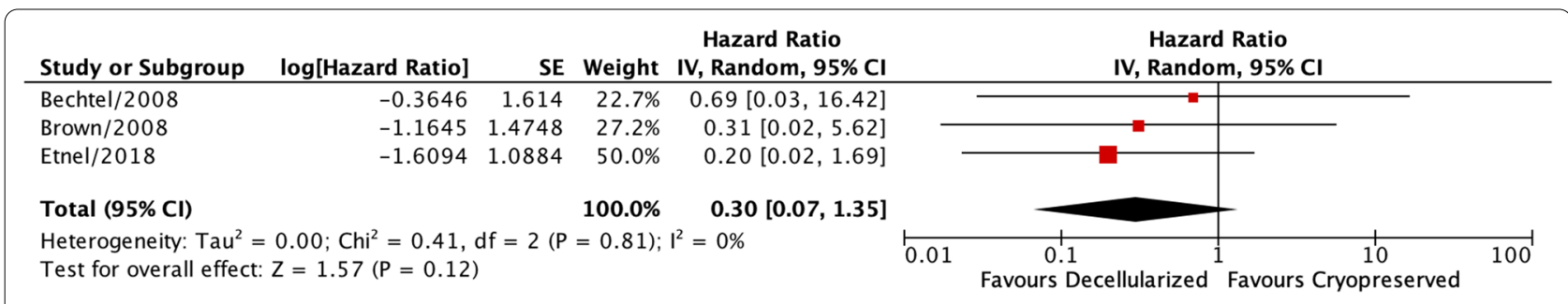

Fig. 5 Forest plot comparing follow-up endocarditis in decellularized allografts versus cryopreserved allografts for patients undergoing right ventricular outflow tract reconstruction during the Ross procedure. IV inverse variance, $\mathrm{Cl}$ confidence interval

\section{Results}

The comprehensive search strategy retrieved 6768 studies, four of which were found to be eligible for analysis (Fig. 1). All studies were retrospective cohort investigations. One of the studies was propensity-matched. Of the included studies, two were multicenter studies. One investigation originated from Germany, the USA, Brazil, and Canada, respectively.

In total, 1687 patients undergoing RVOT reconstruction during the Ross procedure were included; of these, 812 patients received decellularized pulmonary allografts, while 875 patients received cryopreserved pulmonary allografts. Study characteristics are summarized in Table 1. In all studies, patients directly underwent a Ross procedure, in which their native aortic valve was excised, followed by harvesting of the pulmonary autograft taken from their RVOT. Autografts were implanted in the aortic valve position using either the full root replacement or inclusion technique. Two studies reported the use of blood cardioplegia for myocardial protection $[8,10]$. This was followed by the implant of either a decellularized or cryopreserved pulmonary allograft to repair the RVOT. Distal suture lines were made with running 5-0 polypropylene sutures, while proximal suture lines were made with 4-0 continuous polypropylene sutures.

\section{Baseline characteristics}

Total number of patients included in each study ranged from 72 to 858 , while the mean age ranged from 28 to 47 years $(28-47$ years in the decellularized group, and 28.3-46.4 years in the cryopreserved group). Patients in both groups did not significantly differ in age (MD, $-0.92,95 \% \mathrm{CI}-7.15$ to $5.31, P=0.77$ ) (Additional file 1 : Fig. S3.1). Female sex ranged from 17.4 to $35.0 \%$ (17.4$29.0 \%$ in the decellularized group and $24.0-35.0 \%$ in the cryopreserved group). There was no significant difference between decellularized and cryopreserved allografts for percentage of female patients $(26.8 \%$ vs. $25.5 \%$, respectively, $P=0.95$ ) (Additional file 1: Fig. S3.2). The proportion of patients with previous cardiac surgeries ranged from 7.5 to $29 \%$ (11-20.8\% in the decellularized group and $7.5-29 \%$ in the cryopreserved group). Pooled analysis showed no significant difference between the two groups for percentage of patients with previous cardiac surgeries $(15.0 \%$ vs. $10.5 \%$, respectively, $P=0.76)$ (Additional file 1: Fig. S3.3). Preoperative homograft diameter $(\mathrm{mm})$ ranged from 24.6 to $29.1 \mathrm{~mm}(24.6-29.1 \mathrm{~mm}$ in the decellularized group and $25.1-28.2 \mathrm{~mm}$ in the cryopreserved group). Preoperative homograft diameter did not differ significantly between the two groups (MD, 0.08, 95\% CI $-0.67-0.83, P=0.83$ ) (Additional file 1: Fig. S3.4). Hypertension ranged from 12.3 to $32 \%$ (15.4-32\% in the decellularized group and $12.3-23 \%$ in the cryopreserved group). There was no significant difference between decellularized and cryopreserved allografts for percentage of patients with hypertension $(28.4 \%$ vs. $14.3 \%$, respectively, $P=0.21$ ) (Additional file 1: Fig. S3.5). The proportion of patients with smoking/tobacco use ranged from 8.5 to $32 \%$ (9.2-26\% in the decellularized group and $8.5-32 \%$ in the cryopreserved group). Pooled analysis showed no significant difference between the two groups for smoking/tobacco use $(22.3 \%$ vs. $13 \%$, respectively, $P=0.67$ ) (Additional file 1: Fig. S3.6). Chronic obstructive pulmonary disease ranged from 0 to $5 \%(0.8-5 \%$ in the decellularized group and $0-3 \%$ in the cryopreserved group). No significant difference was seen between the decellularized and cryopreserved groups for chronic obstructive pulmonary disease ( $4 \%$ vs. $0.6 \%$, respectively, $P=0.47$ ) (Additional file 1: Fig. S3.7).

\section{Primary outcomes \\ Early mortality}

There was no significant difference between decellularized and cryopreserved allografts for early mortality (OR, $0.65,95 \%$ CI $0.18-2.36, P=0.51) . I^{2}$ was $34 \%$, suggesting moderate heterogeneity (Fig. 2).

\section{Follow-up allograft dysfunction}

Weighted mean follow-up duration for allograft dysfunction was 5.89 years. There was no statistically significant difference between the two groups for follow-up allograft dysfunction (HR, 0.65, 95\% CI 0.20-2.14, $P=0.48$ ). 
Heterogeneity was high between the included studies $\left(I^{2}=84 \%\right)$ (Fig. 3).

\section{Secondary outcomes Reintervention}

The weighted mean follow-up for reintervention was 4.85 years. There was no significant difference between decellularized and cryopreserved allografts for reintervention (HR, 0.54, 95\% CI 0.09-3.12, $P=0.49)$. The studies were highly heterogeneous $\left(I^{2}=87 \%\right)$ (Fig. 4$)$.

\section{Follow-up endocarditis}

The weighted mean follow-up duration for endocarditis was 5.75 years; no statistically significant difference in follow-up endocarditis was found between the two groups (HR, 0.30, 95\% CI 0.07-1.35, $P=0.12$ ). Low heterogeneity between the studies was found $\left(I^{2}=0 \%\right)$ (Fig. 5).

\section{Discussion}

Despite its technical difficulty, the Ross procedure is currently considered a viable alternative to mechanical and bioprosthetic aortic valve replacements, particularly for children and young adults due to its favorable longterm hemodynamics [16]. However, while the pulmonary autograft inserted in the aortic position provides longterm viability, the operation has been criticized due to its association with dysfunction of the pulmonary allograft, including premature stenosis [5] and elevated gradients [17]. Cryopreserved grafts have traditionally been the conduit of choice for RVOT reconstruction during the Ross procedure, but their use has been shown to trigger an increased immune response from host cells. Host hypersensitivity has been proposed as a major cause behind late allograft dysfunction, with risk factors including younger donor age, shorter periods of cryopreservation, and smaller conduit size [18]. To combat this, several centers $[19,20]$ have reported varying success with decellularization techniques, which are believed to provide reduced antigenicity and long-term host compatibility. However, the superiority of decellularized allografts over cryopreserved for RVOT reconstruction in the setting of the Ross has yet to be clearly established with surgeons depending on isolated observational evidence to guide their decision.

In this meta-analysis of 4 studies (1687 patients), we found no significant differences in any explored outcomes between decellularized and cryopreserved allografts for repair of the RVOT in patient undergoing the Ross procedure, including early mortality, follow-up allograft dysfunction, reintervention rates, and follow-up endocarditis. To our knowledge, this is the first meta-analysis directly comparing the clinical outcomes of patients receiving decellularized or cryopreserved allografts for
RVOT reconstruction during the Ross procedure. Previously, Waqanivavalagi and colleagues [21] sought to comprehensively assess the outcomes of decellularized versus cryopreserved heart valves in patients undergoing RVOT reconstruction. Their meta-analysis analysis of 16 studies including 4143 patients found no difference in postoperative mortality (RR, $0.94,95 \% \mathrm{CI} 0.60-1.47, P=0.77$ ), but significantly lower reoperation rates $(\mathrm{RR}, 0.55,95 \% \mathrm{CI}$ $0.36-0.84, P=0.0057)$ for the decellularized group. However, their pooled sample size was comprised of patients with different etiologies requiring outflow tract reconstruction, which may have confounded the mechanisms by which allograft dysfunction arose. The exclusive use of Ross patients in our analysis may be particularly useful for comparing the functionality of decellularized and cryopreserved conduits because the grafts can be precisely sized before sutured into the bed of the transplanted autograft, while preserving the pulmonary tree of the patient [7].

In line with previous literature, our analysis supports the non-inferiority of decellularized pulmonary allograft durability compared to cryopreserved allografts, highlighted by the similar rates of allograft dysfunction and reintervention rates over time between the two groups. Interestingly, in a study of 52 patients receiving outflow tract reconstruction, decellularized allografts demonstrated decreased regurgitation rates at a shortterm follow-up of $19 \pm 13$ months when compared to cryopreserved allografts [22]. However, in a combined series of 82 patients undergoing either Ross or Rastelli procedures at the same institution, Konuma et al. [23] reported no difference in early or late allograft insufficiency or stenosis when assessed at a long-term follow-up of $46 \pm 14$ months. This may suggest a biphasic short-term benefit to decellularized allografts that is lost over time. Our analysis at a long-term follow-up of 5.89 and 4.85 years supports these findings with no difference being shown between the two groups for allograft dysfunction and re-intervention, respectively. Additionally, previous reports have reported similar rates of endocarditis between decellularized and cryopreserved allografts during the Ross procedure [24]. Our analysis is in line with this, showing an overall endocarditis risk of $0.7 \%$ in our cohort at a weight mean follow-up of 5.75 years with no significant difference between the decellularized and cryopreserved groups. The lower risk of endocarditis following the use of pulmonary allografts compared to other conduits for repairing RVOT continues to be a benefit for both decellularized and cryopreserved grafts [24].

The results of our meta-analysis must be interpreted in the context of several limitations. Firstly, moderate to high heterogeneity was present in three of our pooled outcomes. To help ensure we did not over-estimate the 
association between type of pulmonary allograft and clinical outcome, all our analyses were performed using the random-effects model. Secondly, there was a paucity of literature making comparisons between the use of these two conduits for repairing the RVOT in the context of the Ross, with our final analysis consisting of four eligible studies. This limited our ability to pool further baseline characteristics and postoperative outcomes. Further, while our funnel plots showed no evidence of publication bias, having a limited number of eligible studies may have hindered the ability for the funnel plots to show asymmetry. Due to overlapping cohorts, we had to exclude several comparative studies [25-27] from our pooledanalysis, which may have decreased our statistical power and limited our ability to explore additional outcomes, such as long-term mortality and hemodynamics. We also could not assess the immunological profiles and proinflammatory markers in the included patients, which may have provided insight into the mechanisms causing allograft-related dysfunction. Finally, there was heterogeneity in the definitions of outcomes between studies, as some did not report their endpoints using standardized definitions [28].

The Ross procedure continues to show its utility in younger patients requiring aortic valve replacement, showing low rates of reoperation in the first two decades following intervention, regardless of whether a decellularized or cryopreserved allograft was used to repair the RVOT $[29,30]$. Despite this, the operation's use has dramatically decreased in the past decade due to operative complexity and fear of long-term durability [31]. This trend coupled with the advent of valve-in-valve technology [32, 33] for patients requiring repeat aortic valve interventions greatly diminishes the hope of definitive randomized trials comparing the use of decellularized and cryopreserved allografts for RVOT reconstruction during the Ross procedure. Therefore, in the absence of high-evidence trials and larger, multicenter propensitymatched studies, our hope is that this review will provide some guidance for heart teams as they decide the optimal treatment approach for their patients.

\section{Conclusions}

Our results suggest that decellularized allografts have similar clinical outcomes compared to cryopreserved grafts for RVOT reconstruction during the Ross procedure, including early mortality, follow-up valve dysfunction, reintervention, and follow-up endocarditis. Larger propensity-matched studies and randomized control trials are necessary to elucidate the efficacy of decellularized conduits compared to cryopreserved allografts in the setting of the Ross.

\section{Abbreviations}

RVOT: Right ventricular outflow tract; MOOSE: Meta-analysis of observational studies in epidemiology; PRISMA: The preferred reporting items for systematic reviews and meta-analyses; BMI: Body mass index; BSA: Body surface area; NYHA: New York Heart Association; OR: Odds ratio; Cl: Confidence intervals; HR: Hazard ratio.

\section{Supplementary Information}

The online version contains supplementary material available at https://doi. org/10.1186/s43044-021-00226-w.

Additional file 1: Supplemental material including figures S1-S4 and tables S1-S5.

\section{Acknowledgements}

The authors would like to thank the dedicated staff, faculty, and leadership at the Sophie Davis School of Biomedical Education/CUNY School of Medicine for their continued support and inspiration to never stop exploring the field.

\section{Authors' contributions}

AA contributed to the study conceptualization/design, data collection, statistics, data analysis, drafting article, and approval of article. SA contributed to study conceptualization/design, data collection, data analysis, drafting of article, and approval of article. KSV contributed to study conceptualization/ design, data collection, data analysis, critical revision of article, and approval of article. DMM contributed to study conceptualization/design, data collection, data analysis, drafting of article, and approval of article. RP contributed to study conceptualization/design, data collection, data analysis, critical revision of article, and approval of article. DOR contributed to data collection, data analysis, statistics, critical revision of article, and approval of article. SAS contributed to data collection, data analysis, statistics, critical revision of article, and approval of article. PJF contributed to data collection, data analysis, critical revision of article, and approval of article. $\mathrm{KHL}$ contributed to the study conceptualization/design, data analysis, statistics, critical revision of article, and approval of article. All authors read and approved the final manuscript.

\section{Funding}

None.

\section{Availability of data and materials}

All data generated or analyzed during this study are included in this published article [and its Additional file 1].

\section{Declarations}

Ethics approval and consent to participate

This review did not require ethical approval by our institutional review board or individual patient informed consent because no individual patient data were used for analysis.

\section{Consent for publication}

Not applicable.

\section{Competing interests}

None declared.

\section{Author details}

${ }^{1}$ CUNY School of Medicine, 1589 Amsterdam Avenue, New York, NY 10031, USA. ${ }^{2}$ New Dorp High School, New York, NY, USA. ${ }^{3}$ CUNY City College of New York, New York, NY, USA.

Received: 27 July 2021 Accepted: 1 September 2021

Published online: 07 November 2021 


\section{References}

1. El-Hamamsy I, Eryigit Z, Stevens L-M, Sarang Z, George R, Clark L et al (2010) Long-term outcomes after autograft versus homograft aortic root replacement in adults with aortic valve disease: a randomised controlled trial. Lancet 376(9740):524-531

2. Ikonomidis JS, Kratz JM, Crumbley AJ, Stroud MR, Bradley SM, Sade RM et al (2003) Twenty-year experience with the St Jude Medical mechanical valve prosthesis. J Thorac Cardiovasc Surg 126(6):2022-2031

3. Forcillo J, El Hamamsy I, Stevens L-M, Badrudin D, Pellerin M, Perrault $L P$ et al (2014) The perimount valve in the aortic position: twentyyear experience with patients under 60 years old. Ann Thorac Surg 97(5):1526-1532

4. Metras D (1997) Techniques of reconstruction of the right ventricular outflow tract at Ross operation. In: Yacoub MH, Yankah AC, Hetzer R (eds) Cardiac valve allografts. Steinkopff, Heidelberg, pp 201-205. https://doi. org/10.1007/978-3-642-59250-8_20

5. Carr-White GS, Kilner PJ, Hon JK, Rutledge T, Edwards S, Burman ED et al (2001) Incidence, location, pathology, and significance of pulmonary homograft stenosis after the Ross operation. Circulation 104(12 Suppl 1):116-20

6. O'Brien MF, Goldstein S, Walsh S, Black KS, Elkins R, Clarke D (1999) The SynerGraft valve: a new acellular (nonglutaraldehyde-fixed) tissue heart valve for autologous recellularization first experimental studies before clinical implantation. Semin Thorac Cardiovasc Surg 11(4 Suppl 1):194-200

7. Sievers H-H, Stierle U, Schmidtke C, Bechtel M (2003) Decellularized pulmonary homograft (SynerGraft) for reconstruction of the right ventricular outflow tract: first clinical experience. Z Fr Kardiol 92(1):53-59

8. Bechtel JFM, Stierle U, Sievers H-H (2008) Fifty-two months' mean follow up of decellularized SynerGraft-treated pulmonary valve allografts. J Heart Valve Dis 17(1):98-104 (discussion 104)

9. Chauvette V, Bouhout I, Tarabzoni M, Pham M, Wong D, Whitlock R et al (2020) Pulmonary homograft dysfunction after the Ross procedure using decellularized homografts - a multicenter study. J Thorac Cardiovasc Surg. https://doi.org/10.1016/j.jtcvs.2020.06.139

10. Etnel JRG, Suss PH, Schnorr GM, Veloso M, Colatusso DF, Balbi Filho EM et al (2018) Fresh decellularized versus standard cryopreserved pulmonary allografts for right ventricular outflow tract reconstruction during the Ross procedure: a propensity-matched studyt. Eur J Cardiothorac Surg 54(3):434-440

11. Brown JW, Elkins RC, Clarke DR, Tweddell JS, Huddleston CB, Doty JR et al (2010) Performance of the CryoValve* SG human decellularized pulmonary valve in 342 patients relative to the conventional CryoValve at a mean follow-up of four years. J Thorac Cardiovasc Surg 139(2):339-348

12. Stroup DF, Berlin JA, Morton SC, Olkin I, Williamson GD, Rennie D et al (2000) Meta-analysis of observational studies in epidemiology: a proposal for reporting. Meta-analysis of observational studies in epidemiology (MOOSE) group. JAMA 283(15):2008-2012

13. Ottawa Hospital Research Institute [Internet]. [cited 2020 Dec 20]. Available from: http://www.ohri.ca/programs/clinical_epidemiology/oxford. asp

14. RevMan [Internet]. [cited 2020 Dec 20]. Available from: https://training. cochrane.org/online-learning/core-software-cochrane-reviews/revman

15. Higgins JPT, Altman DG, Gøtzsche PC, Jüni P, Moher D, Oxman AD et al (2011) The cochrane collaboration's tool for assessing risk of bias in randomised trials. BMJ 343:d5928

16. Brown JW, Ruzmetov M, Fukui T, Rodefeld MD, Mahomed $Y$, Turrentine MW (2006) Fate of the autograft and homograft following Ross aortic valve replacement: reoperative frequency, outcome, and management. J Heart Valve Dis 15(2):253-259 (discusson 259-260)

17. Bechtel JFM, Müller-Steinhardt M, Schmidtke C, Brunswik A, Stierle U, Sievers $\mathrm{H}-\mathrm{H}$ (2003) Evaluation of the decellularized pulmonary valve homograft (SynerGraft). J Heart Valve Dis 12(6):734-739 (discussion 739-740)

18. Raanani E, Yau TM, David TE, Dellgren G, Sonnenberg BD, Omran A (2000) Risk factors for late pulmonary homograft stenosis after the Ross procedure. Ann Thorac Surg 70(6):1953-1957

19. Navarro FB, da Costa FDA, Mulinari LA, Pimentel GK, Roderjan JG, Vieira ED et al (2010) Evaluation of the biological behavior of decellularized pulmonary homografts: an experimental sheep model. Rev Bras Cir Cardiovasc Orgao Soc Bras Cir Cardiovasc 25(3):377-387

20. Tudorache I, Cebotari S, Sturz G, Kirsch L, Hurschler C, Hilfiker A et al (2007) Tissue engineering of heart valves: biomechanical and morphological properties of decellularized heart valves. J Heart Valve Dis 16(5):567-573 (discussion 574)

21. Waqanivavalagi SWFR, Bhat S, Ground MB, Milsom PF, Cornish J (2020) Clinical performance of decellularized heart valves versus standard tissue conduits: a systematic review and meta-analysis. J Cardiothorac Surg 15(1):260

22. Tavakkol Z, Gelehrter S, Goldberg CS, Bove EL, Devaney EJ, Ohye RG (2005) Superior durability of SynerGraft pulmonary allografts compared with standard cryopreserved allografts. Ann Thorac Surg 80(5):1610-1614

23. Konuma T, Devaney EJ, Bove EL, Gelehrter S, Hirsch JC, Tavakkol Z et al (2009) Performance of CryoValve SG decellularized pulmonary allografts compared with standard cryopreserved allografts. Ann Thorac Surg 88(3):849-854 (discussion 554-555)

24. Sarikouch S, Horke A, Tudorache I, Beerbaum P, Westhoff-Bleck M, Boethig D et al (2016) Decellularized fresh homografts for pulmonary valve replacement: a decade of clinical experience. Eur J Cardio-Thorac Surg Off J Eur Assoc Cardio-Thorac Surg 50(2):281-290

25. da Costa FDA, Takkenberg JJM, Fornazari D, Balbi Filho EM, Colatusso C, Mokhles MM et al (2014) Long-term results of the Ross operation: an 18-year single institutional experience. Eur J Cardiothorac Surg 46(3):415-422

26. Costa F, Dohmen P, Vieira E, Lopes SV, Colatusso C, Pereira EWL et al (2007) Operação de Ross com homoenxertos valvares decelularizados: resultados de médio prazo. Rev Bras Cir Cardiovasc 22(4):454-462

27. da Costa FDA, Colatusso DF, Balbi Filho EM, Marchetti R, Ferreira ADA, Costa MBA et al (2016) 20 years experience with the Ross operation in middle-aged patients: the autologous principle is still alive. Interact Cardiovasc Thorac Surg. https://doi.org/10.1093/icvts/ivw365

28. Akins CW, Miller DC, Turina MI, Kouchoukos NT, Blackstone EH, Grunkemeier GL et al (2008) Guidelines for reporting mortality and morbidity after cardiac valve interventions. J Thorac Cardiovasc Surg 135(4):732-738

29. David TE, David C, Woo A, Manlhiot C (2014) The Ross procedure: outcomes at 20 years. J Thorac Cardiovasc Surg 147(1):85-93

30. Skillington PD, Mokhles MM, Takkenberg JJM, Larobina M, O'Keefe M, Wynne R et al (2015) The Ross procedure using autologous support of the pulmonary autograft: techniques and late results. J Thorac Cardiovasc Surg 149(2 Suppl):S46-52

31. Reece TB, Welke KF, O'Brien S, Grau-Sepulveda MV, Grover FL, Gammie JS (2014) Rethinking the Ross Procedure in Adults. Ann Thorac Surg 97(1):175-181

32. Hameed I, Ahmed A, Ullah N, Salemi A (2020) Valve-in-valve transcatheter aortic valve replacement: a review of procedural details, safety, and clinical implications. Cardiol Rev 28(6):291-294

33. Ahmed A, Levy KH (2021) Valve-in-valve transcatheter aortic valve replacement versus redo surgical aortic valve replacement: A systematic review and meta-analysis. J Card Surg 36(7):2486-2495

\section{Publisher's Note}

Springer Nature remains neutral with regard to jurisdictional claims in published maps and institutional affiliations. 